\title{
Narrowband filters for the FUV range
}

\author{
Luis Rodríguez-de Marcos¹, Juan I. Larruquert ${ }^{*}$, José A. Méndez¹, José A. Aznárez ${ }^{1}$, Liping Fu². \\ ${ }^{1}$ GOLD, Instituto de Óptica-Consejo Superior de Investigaciones Científicas (CSIC) \\ Serrano 144, 28006 Madrid, Spain \\ ${ }^{2}$ Center for Space Science and Applied Research (CSSAR), Chinese Academy of Sciences (CAS)
}

\begin{abstract}
We address the design, fabrication, and characterization of transmittance filters for the Ionosphere Photometer instrument (IP), developed by the Center for Space Science and Applied Research (CSSAR). IP, a payload of Feng-Yun 3D meteorological satellite, to be launched on 2016, is aimed to perform photometry measurements of Earth's ionosphere by the analysis of the OI $\left(135.6 \mathrm{~nm}\right.$ ) spectral line and $\mathrm{N}_{2}$ Lyman-Birge-Hopfield (LBH, 140-180 nm) band, both of them in the far ultraviolet (FUV) range.

The most convenient procedure to isolate a spectral band is the use of tunable transmittance filters. In many applications the intensity of the ultraviolet, visible and infrared background is higher than the intensity of the target FUV lines; therefore one of the most important requirements for transmittance filters is to reject (by reflecting and/or by absorbing) as efficiently as possible the visible and close ranges. In the FUV range, $\left(\mathrm{Al} / \mathrm{MgF}_{2}\right)_{\mathrm{n}}$ transmittance filters are the most common, and they are suitable to reject the visible and adjacent ranges. These materials present unique properties in this range: $\mathrm{MgF}_{2}$ is transparent down to $\sim 115 \mathrm{~nm}$ and $\mathrm{Al}$ has a very low refractive index in the FUV that contrasts well with $\mathrm{MgF}_{2}$. Narrowband tunable filters with very low transmittance at long wavelengths are achievable.

The main data on the preparation and characterization of IP filters by Grupo de Óptica de Láminas Delgadas (GOLD) is detailed. In this proceeding we present $\left(\mathrm{Al} / \mathrm{MgF}_{2}\right)_{3}$ filters peaked at either $135.6 \mathrm{~nm}$ or at the center of the LBH band $(\sim 160 \mathrm{~nm})$. Filters were characterized in the 125-800 $\mathrm{nm}$ range (143-800 nm range for the LBH filter). After some storage in a desiccator, both coatings kept a transmittance of $\sim 0.14$ at their target wavelengths, with visible-topeak transmittance ratios of $1.2 \cdot 10^{-4}$ (OI filter) and $1.3 \cdot 10^{-4}$ (LBH filter). One filter tuned at each target wavelength was exposed to $\sim 300 \mathrm{~Gy}{ }^{60} \mathrm{Co}$ gamma dose, with no significant transmittance change.
\end{abstract}

Keywords: Coatings, Far Ultraviolet, Atmosphere Physics, Transmittance Filters, Space Optics

\section{INTRODUCTION}

This research describes the development of FUV transmission filters for IP instrument (Ionosphere Photometer). IP instrument is a newly-designed instrument for observing the nadir viewing Earth airglow at OI 135.6 $\mathrm{nm}$ emission and $\mathrm{N}_{2} \mathrm{LBH}$ emission and receiving the horizontal information with a spatial resolution of about $1.6^{\circ} \times 3.5^{\circ}$. This payload is aimed for the analysis of the global response of the ionosphere and thermosphere to solar and geomagnetic disturbances. IP is being developed by Center for Space Science and Applied Research (CSSAR), and it is scheduled to fly as a payload on the Feng Yun-3D meteorological satellite in 2016.

The ionosphere is the ionized part of the upper atmosphere, and it is situated at an altitude of between 60 and $2000 \mathrm{Km}$ It approximately behaves as a plasma. It is under low pressure, and its elements are ionized and contain the same number of positive and negative charges, which results in a conductive medium but it is electrically neutral. The existence of these charged particles has a great influence on the propagation of electromagnetic waves, particularly on radio waves. The ionosphere is basically composed of gases such as $\mathrm{N}_{2}, \mathrm{O}_{2}$ and $\mathrm{O}$ (atomic oxygen), which are ionized

*j.larruquert@csic.es; phone: 34- 915618806 ext 330; fax: 34-914117651 
by solar radiation, especially FUV, EUV, and X-ray radiation. Such ions and electrons tend to recombine, emitting photons at characteristic wavelengths. IP instrument is designed to perform observations in the FUV, particularly to measure the oxygen airglow at the OI line $(135.6 \mathrm{~nm})$, and the molecular emission of $\mathrm{N}_{2}$ at the Lyman-Birge-Hopfield band (LBH, 140-180 nm). These line and band are expected to provide valuable information about the ionosphere and its inner changes. As an example, when a solar storm occurs, there is a falling density of $\mathrm{O}$ atoms in the ionosphere, while the density of the $\mathrm{N}_{2}$ molecules remains stable. This results in a change on the ionosphere $\mathrm{O} / \mathrm{N}_{2}$ ratio, and therefore, on the ratio between the emission lines of $\lambda(135.6 \mathrm{~nm})$ and $\lambda(\mathrm{LBH})$. Thus, IP requires an efficient way to select either the OI line or the LBH band while blocking the near UV (NUV)-visible-near IR (NIR) radiation. IP uses transmittance filters to select a key wavelength or band and block the stray light, especially the long wavelength starlight $(>200 \mathrm{~nm})$.

First FUV transmittance filters were developed in the 1960 `s, and were based on the $\mathrm{Al} / \mathrm{MgF}_{2}$ system. $\mathrm{MgF}_{2}$ is the most common FUV spacer material down to its cutoff at $\sim 115 \mathrm{~nm}$, and Al presents high absorption and reflectance, and hence small transmittance, not only in the NUV and visible ranges but also in the FUV. Schroeder ${ }^{1}$ was the first to report on filters designs for the $\sim 150-250 \mathrm{~nm}$ range, and to prepare filters for the wavelengths of $\sim 185 \mathrm{~nm}$ and $\sim 255 \mathrm{~nm}$; all filters were based on the $\mathrm{Al} / \mathrm{MgF}_{2}$ system. In 1966, Bates and Bradley developed $\left(\mathrm{Al}^{2} / \mathrm{MgF}_{2}\right)_{2}$ filters down to $\sim 178$ $\mathrm{nm}$. They were the first on reporting second-order filters as well as the necessity to protect the outermost Al layer from oxidation with an additional $\mathrm{MgF}_{2}$ layer on top of $\mathrm{Al}$; they detected a transmittance reduction at the peak along with a shift towards longer wavelengths after two weeks of filter exposure to atmosphere. In 1968, Harrison ${ }^{3}$ developed $\left(\mathrm{Al} / \mathrm{MgF}_{2}\right)_{2}$ filters down to $130 \mathrm{~nm}$.

After these pioneering articles in the 1960's, several authors continued in the 1970's (and beyond) developing filters for wavelengths down to $\sim 120 \mathrm{~nm}^{4,5,6}$. A remarkable work about the first $\left(\mathrm{Al} / \mathrm{MgF}_{2}\right)_{3}$ filters centered at $121.6 \mathrm{~nm}$ was presented by Malherbe ${ }^{7}$ in 1974 . He achieved an impressive peak transmittance value of $\sim 0.15$ with a 9-nm bandwidth. The coating was deposited on a LiF substrate. Another interesting work was published in 1974 by Spiller ${ }^{8}$. He developed $\left(\mathrm{Al} / \mathrm{MgF}_{2}\right)_{2}$ filters of orders 1, 2 and 4, and he observed that discrepancies between theoretical and experimental results were larger on high-order interference filters compared with first order filters, and, according to him, those discrepancies could not be explained by different optical constants of the evaporated materials, or by contamination, or by structural differences of the very thin films, or scattering or absorption in the $\mathrm{MgF}_{2}$ spacer films, but to the $\mathrm{MgF}_{2}$ surface roughness "propagated" to the $\mathrm{Al}$ film, causing a coupling between the incident light into the $\mathrm{Al}$ surface plasmon, which results in an absorption increase. The latter suggests the presence of an additional handicap for the development of filters peaked at wavelengths longer than $\sim 153 \mathrm{~nm}$, the resonant wavelength for surface plasmon generation on the $\mathrm{MgF}_{2} / \mathrm{Al}$ interface.

Even though ample knowledge for the preparation of transmittance filters has been already reported, the fabrication of efficient filters is still difficult, due to technical difficulties involved in filter preparation and to some evolution of filters over time, where several mechanisms such as density changes, oxidation, Al surface plasmon effects or contaminants might contribute to modify the optical properties of filters upon ageing. The latter issues, along with the very high out-of-band rejection required by IP's filter specifications, make the development of the filters for the present mission a challenging work.

In this proceeding we address the development of two sets of narrowband transmittance filters for IP peaked at either $135.6 \mathrm{~nm}$ or at the LBH band $(\sim 160 \mathrm{~nm})$, with the requirement to strongly reject the out-of-band, particularly the visible and close ranges. The coatings were based on $\left(\mathrm{Al} / \mathrm{MgF}_{2}\right)_{3}$ multilayers. We also present filter characterization after exposure to gamma radiation.

\section{EXPERIMENTAL EQUIPMENT}

$\left(\mathrm{Al} / \mathrm{MgF}_{2}\right)_{3}$ transmittance filters were deposited in a $75-\mathrm{cm}$ diameter, $100-\mathrm{cm}$ height cylindrical deposition chamber, pumped with a Velco $250 \mathrm{~A}$ cryo system, with a base pressure of $10^{-6} \mathrm{~Pa}$. The chamber is placed in an ISO-6 clean room. Fig. 1 shows a picture of the chamber. 


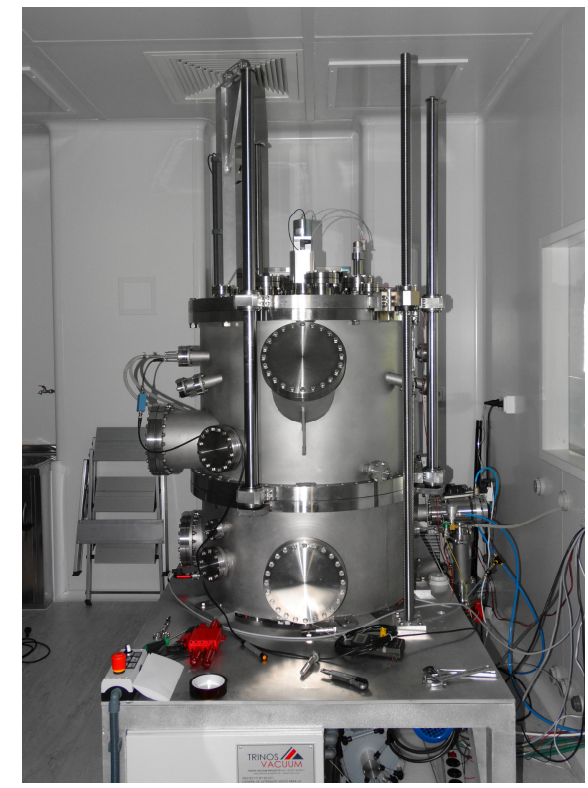

Fig.1. 75-cm diameter, 100- cm height deposition chamber.

Films of $\mathrm{Al}$ and $\mathrm{MgF}_{2}$ were deposited by evaporation using $\mathrm{W}$ multi-stranded filaments (Al) and $\mathrm{W}$ boats $\left(\mathrm{MgF}_{2}\right)$. The distance between the sources and the substrate holder (able to hold up to 3 substrates) was $50 \mathrm{~cm}$. In order to improve uniformity, the substrate holder rotated at $\sim 1 \mathrm{~Hz}$. Material purity was $99.999 \%$ for $\mathrm{Al}$ and VUV-grade for $\mathrm{MgF}_{2}$. Deposition rate were $\sim 1.6(\mathrm{Al})$ and $1.7\left(\mathrm{MgF}_{2}\right) \mathrm{nm} / \mathrm{s}$; during deposition, pressure increased to $\sim 7 \cdot 10^{-6}$ and $\sim 4 \cdot 10^{-6}$ $\mathrm{Pa}$ for $\mathrm{MgF}_{2}$ and $\mathrm{Al}$, respectively. Film thickness was measured with a quartz-crystal monitor, which had been previously calibrated through ellipsometry and profilometry measurements.

Filter transmittance was measured in the FUV in GOLD's reflectometer system. It has a grazing-incidence, toroidal-grating monochromator, in which the entrance and exit arms are $146^{\circ}$ apart. The monochromator covers the $12.5-200 \mathrm{~nm}$ spectral range with two Pt-coated diffraction gratings that operate in the long $(250 \mathrm{l} / \mathrm{mm})$ or in the short $(950 \mathrm{l} / \mathrm{mm})$ spectral range. A windowless capillary discharge lamp was used in this work. The lamp is fed with various pure gases or gas mixtures with which it can generate many spectral lines to cover the spectral range of interest. The beam divergence was $\sim 1.7 \mathrm{mrad}$ and angle accuracy is estimated as $\pm 0.1^{\circ}$. The sample holder can fit samples up to an area of $50.8 \times 50.8 \mathrm{~mm}^{2}$. A channel electron multiplier with a CsI-coated photocathode was used as the detector. Transmittance was obtained by alternately measuring the incident intensity and the intensity transmitted through the sample.

At wavelengths longer than $190 \mathrm{~nm}$, filter transmittance was measured using a Perkin-Elmer Lambda 9 spectrophotometer. The spectrophotometer is designed to measure transmittance values not smaller than $10^{-4}$. Since filters with a transmittance smaller than this value had to be measured for this application, the measurement procedure was optimized, which enabled us to measure transmittance values as low as $10^{-6}$. This was done by working in two directions. One was to block parasitic radiation coming from reflections at various surfaces within the instrument. The other direction was to add a neutral filter in the reference beam of the spectrophotometer in order to shift the dynamic range of the instrument to smaller transmittance by various orders of magnitude. The neutral filter transmittance was measured for each sample with the spectrophotometer by placing it in the sample beam. The spectrophotometer as a standard measures transmittance at $0^{\circ}$ incidence angle with non-polarized radiation. But with this configuration, the high reflectance of present filters at long wavelengths would add a high undesired background signal. To avoid this, filters were slightly tilted to a maximum of $1.5^{\circ}$ away from the normal.

A filter gamma-ray irradiation test was performed at "Unidad de Irradiación Náyade", Centro de Investigaciones Energéticas, Medioambientales y Tecnológicas (CIEMAT). The filter to be irradiated was placed in a sealed container. The sample container is placed in a water pool, where there are cylindrical sample containers to accommodate ${ }^{60} \mathrm{Co}$; the container rotates to improve irradiation uniformity. The dimensions of the pool where the filter 
container is placed for irradiation are 1,2 $\mathrm{m}$ side and 4,5 $\mathrm{m}$ deep, which provides enough biological shielding for $100.000 \mathrm{Ci}$ of ${ }^{60} \mathrm{Co}$. Upon decay, ${ }^{60} \mathrm{Co}$ emits two gamma rays with energies of 1.17 and $1.33 \mathrm{MeV}$. The dose/h available with the selected configuration was $\sim 121 \mathrm{~Gy} / \mathrm{h}$, therefore test samples were exposed to gamma radiation for $2 \mathrm{~h}$ and 30 min in order to obtain the required 300 Gy dose.

\section{OPTICAL REQUIREMENTS}

Tables 1 and 2 display the requirements pursued for the filters.

Table 1. Requirements for the filters peaked at $135.6 \mathrm{~nm}$.

\begin{tabular}{|c|c|}
\hline \multicolumn{2}{|c|}{ Specifications } \\
\hline Central wavelength & $135.6 \mathrm{~nm}$ \\
\hline Peak tolerance & $\pm 2.5 \mathrm{~nm}$ \\
\hline Bandwidth (FWMH) & $\leq 15 \mathrm{~nm}$ \\
\hline Minimum peak transmittance at $0^{\circ}$ & $\geq 0.10$ \\
\hline $0^{\circ}, 10^{\circ}$ and $16^{\circ}$ transmittance: & $\begin{array}{l}\text { Provide the transmittance at incidence angle } \\
\text { of } 0^{\circ}, 10^{\circ} \text { and } 16^{\circ}\end{array}$ \\
\hline \multicolumn{2}{|c|}{ Out of band rejection } \\
\hline $\mathrm{T}_{190 \mathrm{~nm}} / \mathrm{T}_{135.6 \mathrm{~nm}}$ & $<0.01$ \\
\hline $\mathrm{T}_{250 \mathrm{~nm}} / \mathrm{T}_{135.6 \mathrm{~nm}}$ & $<0.001$ \\
\hline $\mathrm{T}_{300 \mathrm{~nm}} / \mathrm{T}_{135.6 \mathrm{~nm}}$ & $<3 \cdot 10^{-4}$ \\
\hline $\mathrm{T}_{350 \mathrm{~nm}} / \mathrm{T}_{135.6 \mathrm{~nm}}$ & $\leq 3 \cdot 10^{-4}$ \\
\hline $\mathrm{T}_{\text {visible }} / \mathrm{T}_{135.6 \mathrm{~nm}}$ & $\leq 3 \cdot 10^{-4}$ \\
\hline \multicolumn{2}{|c|}{ Size } \\
\hline Diameter & $16 \mathrm{~mm}$ \\
\hline Active Area Diameter & $14 \mathrm{~mm}$ \\
\hline Thickness & $1.5 \mathrm{~mm}$ \\
\hline \multicolumn{2}{|c|}{ Anti-irradiation required test } \\
\hline \multicolumn{2}{|c|}{$>3 \times 10^{4} \mathrm{rad}(\mathrm{Si})\left(\right.$ For ${ }^{60} \mathrm{Co}: 3 \times 10^{2}$ Gy dose in air) } \\
\hline
\end{tabular}

Table 2. Requirements for the filters peaked at $160 \mathrm{~nm}$.

\begin{tabular}{|c|c|}
\hline \multicolumn{2}{|c|}{ Specifications } \\
\hline Central wavelength & $160.0 \mathrm{~nm}$ \\
\hline Bandwidth (FWMH) & $\sim 20 \mathrm{~nm}$ \\
\hline Minimum peak transmittance at $0^{\circ}$ & $\geq 0.10$ \\
\hline $0^{\circ}, 10^{\circ}$ and $16^{\circ}$ transmittance: & $\begin{array}{l}\text { Provide the transmittance at incidence angle } \\
\text { of } 0^{\circ}, 10^{\circ} \text { and } 16^{\circ}\end{array}$ \\
\hline \multicolumn{2}{|c|}{ Out of band rejection } \\
\hline $\mathrm{T}_{\lambda \leq 135.6 \mathrm{~nm}} / \mathrm{T}_{160 \mathrm{~nm}}$ & $<0.005$ \\
\hline $\mathrm{T}_{200 \mathrm{~nm}} / \mathrm{T}_{160 \mathrm{~nm}}$ & $<0.01$ \\
\hline $\mathrm{T}_{250 \mathrm{~nm}} / \mathrm{T}_{160 \mathrm{~nm}}$ & $<0.001$ \\
\hline $\mathrm{T}_{300 \mathrm{~nm}} / \mathrm{T}_{160 \mathrm{~nm}}$ & $<3 \cdot 10^{-4}$ \\
\hline $\mathrm{T}_{350 \mathrm{~nm}} / \mathrm{T}_{160 \mathrm{~nm}}$ & $\leq 3 \cdot 10^{-4}$ \\
\hline $\mathrm{T}_{\text {visible }} / \mathrm{T}_{160 \mathrm{~nm}}$ & $\leq 3 \cdot 10^{-4}$ \\
\hline \multicolumn{2}{|c|}{ Size } \\
\hline Diameter & $16 \mathrm{~mm}$ \\
\hline Active Area Diameter & $14 \mathrm{~mm}$ \\
\hline Thickness & $1.5 \mathrm{~mm}$ \\
\hline Anti-irradiation required test & $\begin{array}{l}\text { required test } \\
3 \times 10^{2} \text { Gy dose in air) }\end{array}$ \\
\hline
\end{tabular}




\section{RESULTS}

4.1 Transmittance filters for the OI line $(135.6 \mathrm{~nm})$ and for the central part of the $\mathrm{N}_{2}$ Lyman-BirgeHopfield band (LBH, $\sim 160 \mathrm{~nm}$ ).

Present coatings have been designed in order to achieve the requirements presented in tables 1 and 2 . The first step was to select the materials. As presented in the introduction, multilayers based on $\mathrm{Al}$ combined with $\mathrm{MgF}_{2}$ have been extensively used for narrowband transmittance filters peaked above $\sim 115 \mathrm{~nm} . \mathrm{MgF}_{2}$ has a low absorption at both of the present target wavelengths, and Al efficiently rejects the NUV-visible-NIR ranges and unfortunately also at the peak FUV wavelength, so that the total $\mathrm{Al}$ thickness has to be optimized to combine enough transmittance at the target wavelength and a high enough rejection of the out of band. The optical constant data available in the literature for $\mathrm{Al}^{9,10}$ were used in the design. About $\mathrm{MgF}_{2}$, a non-published data set was used; this set was obtained from optical measurements on thin films. $\mathrm{MgF}_{2}$ (vendors: Crystran and Fairfield), and quartz (vendor: Crystran) substrates were used for the coatings peaked at 135.6 and at $160 \mathrm{~nm}$, respectively. Quartz was selected as the substrate because of the strong absorption below its cut-off at $\sim 146 \mathrm{~nm}$, which ensures zero transmittance at $135.6 \mathrm{~nm}$. Substrates were 16-mm diameter and 1.5-mm thick disks. Three-bilayer $\left(\mathrm{Al} / \mathrm{MgF}_{2}\right)_{3}$, first-order coatings were designed with peak transmittance at wavelengths $\sim 2.5 \mathrm{~nm}$ shorter than either 135.6 or $160 \mathrm{~nm}$, respectively, since filters may undergo a shift to longer wavelengths. Besides the flight filters, additional filters had been prepared for the engineering model of $\mathrm{IP}^{11}$ instrument; ageing was studied in the engineering model filters, and an average shift of $\sim 2.5 \mathrm{~nm}$ towards longer wavelengths was observed. This previous analysis led us to situate the peak of the present filters at the short edge of the central wavelength tolerated range. Designs are displayed in table 3.

Table 3. Designs for the filters peaked at 135.6 and $160 \mathrm{~nm}$.

\begin{tabular}{|c|c|}
\hline \multicolumn{2}{|c|}{ Filter designs. Optical layer thickness is given in quarterwaves } \\
\hline Filter peaked at $135.6 \mathrm{~nm}$ & Filter peaked at $160.0 \mathrm{~nm}$ \\
\hline Substrate $/ \mathrm{Al} / \mathrm{MgF}_{2} / \mathrm{Al} / \mathrm{MgF}_{2} / \mathrm{Al} / \mathrm{MgF}_{2}$ & Substrate $/ \mathrm{Al} / \mathrm{MgF}_{2} / \mathrm{Al} / \mathrm{MgF}_{2} / \mathrm{Al} / \mathrm{MgF}_{2}$ \\
\hline Substrate/0.025/0.936/0.052/0.965/0.023/1.422 & Substrate $/ 0.027 / 1.084 / 0.053 / 1.104 / 0.027 / 1.101$ \\
\hline
\end{tabular}

An image of the filter designed at $\sim 160 \mathrm{~nm}$ placed in the holder for transmittance measurements is presented in Fig. 2.

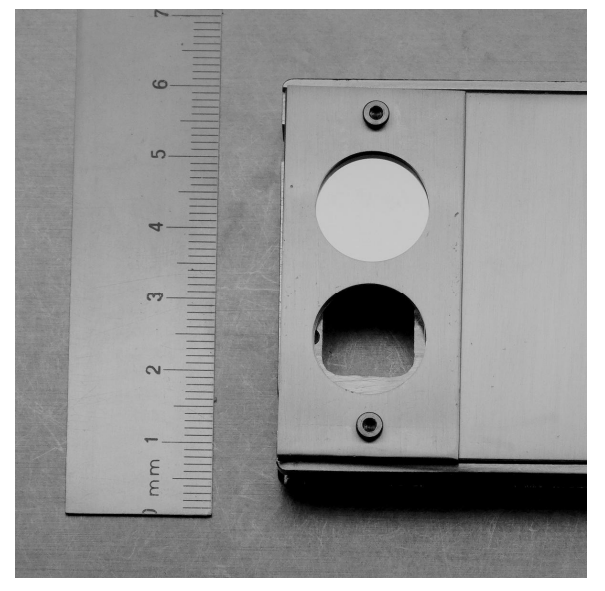

Fig. 2. Picture of the filter designed at $\sim 160 \mathrm{~nm}$ inside the holder for transmittance measurements. 
Filters were initially measured after a short contact to atmosphere of $\sim 1 \mathrm{~h}$ (fresh) and again after aged in a desiccator. Figures 3 and 4 show the transmittance at normal incidence for both fresh and aged filters. Aged measurements were performed in the 125-800 nm range between 3 and 5 weeks of storage in a desiccator. Transmittance at $10^{\circ}$ and at $16^{\circ}$ for aged samples is also displayed in the $125-150 \mathrm{~nm}$ range (filters for the OI line), or in the 143-187 nm range (filters for the center of the LBH band). For measurements at nonnormal incidence, we proceeded in the following way in order to avoid the effect of monochromator-induced partial polarization on the incident beam. For the filters peaked at $160 \mathrm{~nm}$, we used a commercial Rochon prism polarizer, which was oriented at $45^{\circ}$ with respect to the two following planes: 1) the plane of incidence, and 2) the plane given by the propagation direction and the filter rotation axis. Therefore, we converted the partially polarized radiation into linearly polarized radiation at $45^{\circ}$ with respect to the incidence plane, which results in equal intensity components of light with electric field both parallel and perpendicular to the incidence plane, so that for photometry measurements we obtain the same results as if we had nonpolarized light. The Rochon polarizer does not work below $\sim 135 \mathrm{~nm}$, so that it could not be used for the filters peaked at $135.6 \mathrm{~nm}$, Recently, a new transmittance polarizer operating in a range centered at $121.6 \mathrm{~nm}$ has been developed $^{12}$; such polarizers can be also designed to cover wavelengths as long as $135 \mathrm{~nm}$, but such a polarizer was not available. Not having a polarizer below $135 \mathrm{~nm}$, we performed measurements in two perpendicular incidence planes, and the average of these measurements over the two planes must equal the transmittance of the filter for non-polarized radiation.
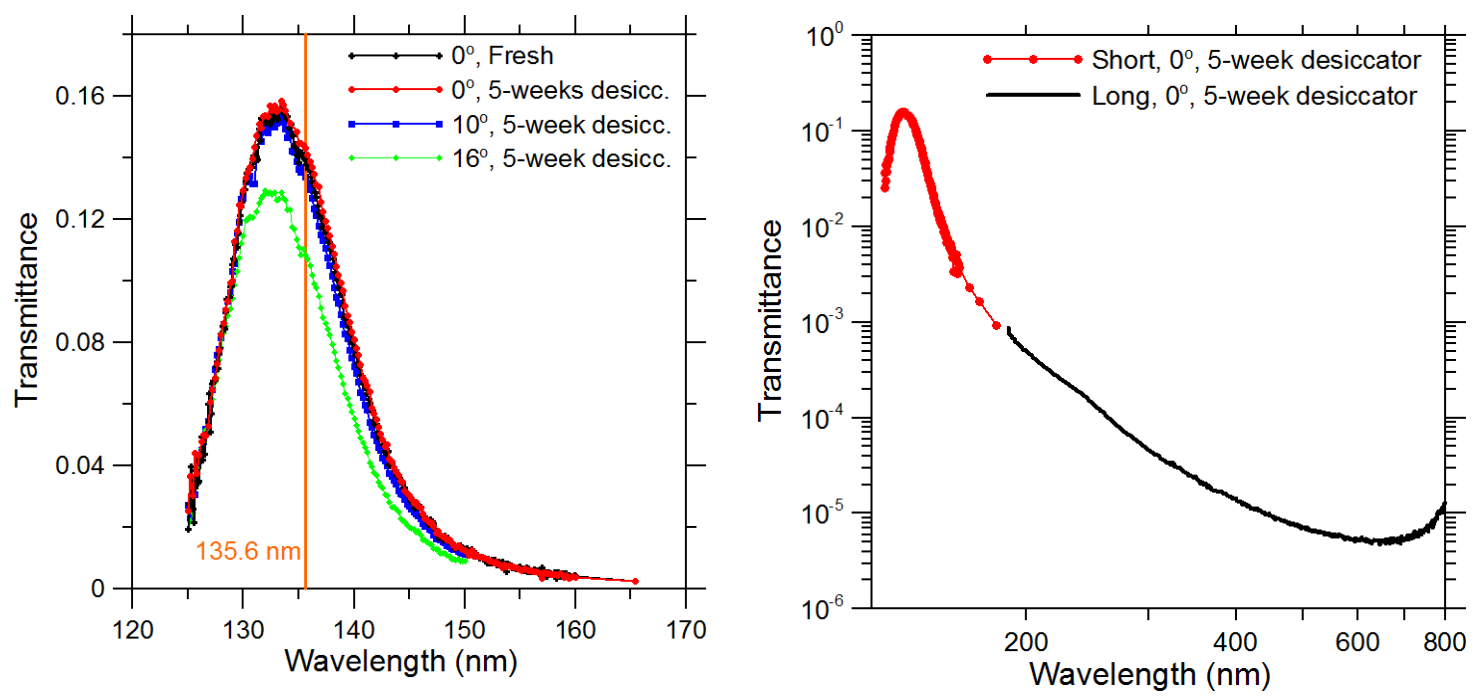

Fig. 3. Transmittance as a function of wavelength for a filter peaked at $135.6 \mathrm{~nm}$ both fresh (with a short exposure to the atmosphere) and after storage of 5 weeks in a desiccator. Transmittance of the aged sample at $10^{\circ}$ and $16^{\circ}$ is also displayed. Left and right: transmittance and its logarithm, respectively. 

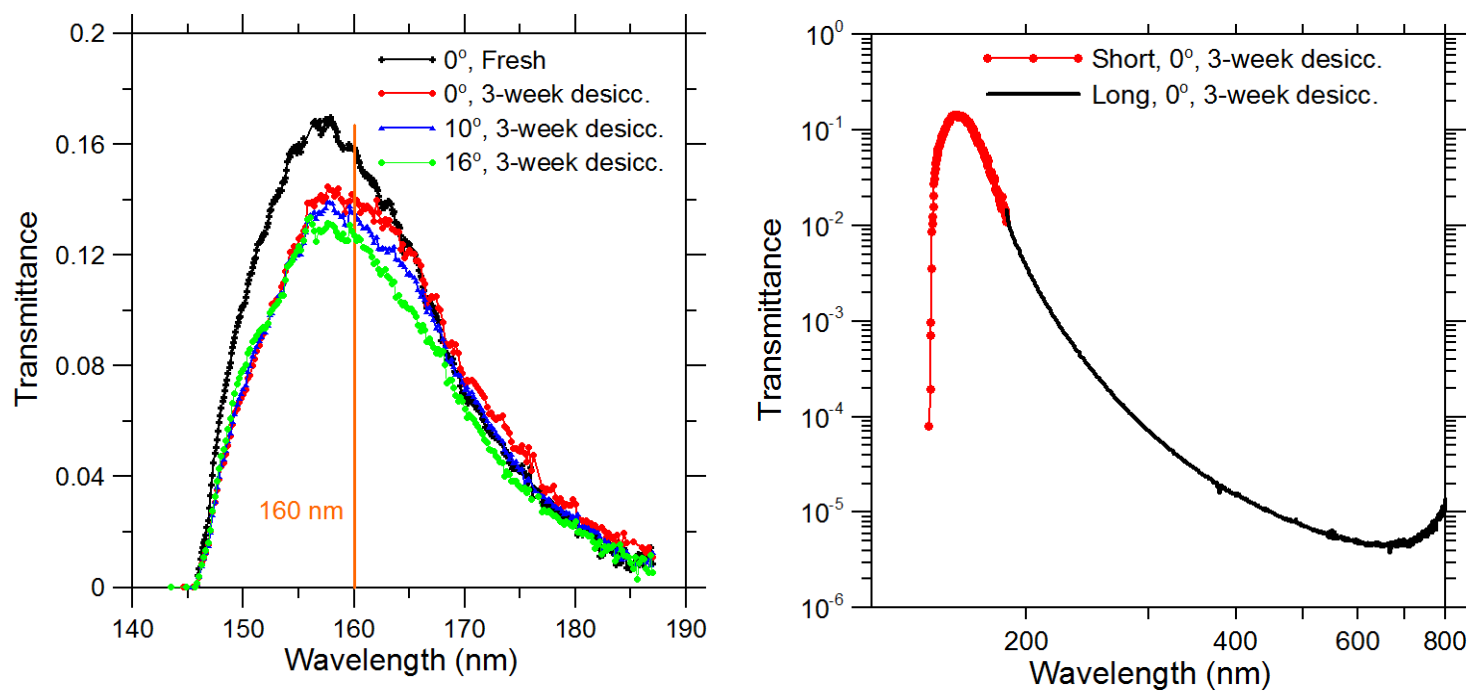

Fig. 4. Transmittance as a function of wavelength for a filter peaked at $160 \mathrm{~nm}$ both fresh (with a short exposure to the atmosphere) and after storage of 3 weeks in a desiccator. Transmittance of the aged sample at $10^{\circ}$ and $16^{\circ}$ is also displayed. Left and right: transmittance and its logarithm, respectively.

Transmittance at target wavelengths and FWHM for aged samples were 0.143 and $12.4 \mathrm{~nm}$ (135.6-nm filter) and 0.140 and $21.2 \mathrm{~nm}(160.0-\mathrm{nm}$ filter). The 135.6-nm filter peak did not shift over the ageing period, whereas the ones peaked at $160 \mathrm{~nm}$ shifted towards the target wavelength over time, therefore transmittance maxima of aged filters were at $133.4 \mathrm{~nm}$ and at $159.0 \mathrm{~nm}$ for the filters displayed in Figs. 3 and 4, respectively. As mentioned in the introduction, a peak shift of $\sim 2.5 \mathrm{~nm}$ was detected by Bates and Bradley ${ }^{2}$ for filters peaked at $\sim 196 \mathrm{~nm}$. They attributed the shift to structural changes in the magnesium fluoride spacer layer, increasing absorption of the aluminum films because of continuing oxidation or strain relief at the aluminum-magnesium fluoride boundaries.

Regarding the out-of-band transmittance, a strong rejection of the NUV and visible ranges was measured in both kinds of filters. Table 4 depicts the transmittance ratios obtained on aged samples. Although no measurements were done below $143 \mathrm{~nm}$ for the $160 \mathrm{~nm}$-peaked filters, a virtual zero transmittance value at $135.6 \mathrm{~nm}$ is guaranteed for the 160-nm filter due to the full absorption of the quartz substrate.

Table 4. Comparison between the pursued values and experimental.

\begin{tabular}{|c|c|c|}
\hline \multicolumn{3}{|c|}{ Out of band rejection (OI line) } \\
\hline & Specifications & Experimental (5 weeks) \\
\hline $\mathrm{T}_{190 \mathrm{~nm}} / \mathrm{T}_{135.6 \mathrm{~nm}}$ & $<0.01$ & 0.0050 \\
\hline $\mathrm{T}_{250 \mathrm{~nm}} / \mathrm{T}_{135.6 \mathrm{~nm}}$ & $<0.001$ & 0.00097 \\
\hline $\mathrm{T}_{300 \mathrm{~nm}} / \mathrm{T}_{135.6 \mathrm{~nm}}$ & $<3 \cdot 10^{-4}$ & $3.2 \cdot 10^{-4}$ \\
\hline $\mathrm{T}_{350 \mathrm{~nm}} / \mathrm{T}_{135.6 \mathrm{~nm}}$ & $\leq 3 \cdot 10^{-4}$ & $1.7 \cdot 10^{-4}$ \\
\hline $\mathrm{T}_{\text {visible }} / \mathrm{T}_{135.6 \mathrm{~nm}}$ & $\leq 3 \cdot 10^{-4}$ & $<1.2 \cdot 10^{-4}$ \\
\hline \multicolumn{3}{|c|}{ Out of band rejection (center of LBH band) } \\
\hline & Specifications & Experimental (3 weeks) \\
\hline $\mathrm{T}_{\lambda \leq 135.6 \mathrm{~nm}} / \mathrm{T}_{160 \mathrm{~nm}}$ & $<0.005$ & 0 (expected) \\
\hline $\mathrm{T}_{200 \mathrm{~nm}} / \mathrm{T}_{160 \mathrm{~nm}}$ & $<0.01$ & 0.026 \\
\hline $\mathrm{T}_{250 \mathrm{~nm}} / \mathrm{T}_{160 \mathrm{~nm}}$ & $<0.001$ & 0.0021 \\
\hline $\mathrm{T}_{300 \mathrm{~nm}} / \mathrm{T}_{160 \mathrm{~nm}}$ & $<3 \cdot 10^{-4}$ & $5.1 \cdot 10^{-4}$ \\
\hline $\mathrm{T}_{350 \mathrm{~nm}} / \mathrm{T}_{160 \mathrm{~nm}}$ & $\leq 3 \cdot 10^{-4}$ & $2.1 \cdot 10^{-4}$ \\
\hline $\mathrm{T}_{\text {visible }} / \mathrm{T}_{160 \mathrm{~nm}}$ & $\leq 3 \cdot 10^{-4}$ & $<1.3 \cdot 10^{-4}$ \\
\hline
\end{tabular}

Although NUV filter rejection was slightly smaller than the pursued values, the design gave priority to both the peak efficiency and to a strong rejection of the visible range. 


\subsection{Irradiation tests}

FUV transmittance filters based on $\mathrm{Al} / \mathrm{MgF}_{2}$ have been used for space applications for decades and hence they are expected to be stable under many of the harsh components of space environment. In the present application, the filters must be stable upon exposure to a gamma ray dose of at least $300 \mathrm{~Gy}$ of ${ }^{60} \mathrm{Co}$. Keffer et al. ${ }^{13}$ exposed different materials and substrates (including $\mathrm{MgF}_{2}$ as film and substrate) to radiation and they concluded that $\mathrm{MgF}_{2}$, as a substrate or thin film, should experience less than $5 \%$ transmittance change from exposure to up to $2500 \mathrm{~Gy}$. We did not find data on the effect of gamma radiation over the $\mathrm{Al} / \mathrm{MgF}_{2} \mathrm{FUV}$ transmittance filters.

Irradiation tests were carried out on one aged filter tuned at the OI line and one at the LBH band. Irradiated filters were not later selected as flight filters. Irradiation was performed at the "Unidad de Irradiación Náyade", CIEMAT. Samples were exposed to a ${ }^{60} \mathrm{Co}$ gamma dose of $300 \mathrm{~Gy}$. We irradiated not only the filters but also uncoated substrates of $\mathrm{MgF}_{2}$ and quartz, which were used as witnesses in order to discard that an eventual substrate degradation might be taken for a coating degradation. Both filters and uncoated substrates were kept inside fluoroware containers during the test. Filters to be irradiated and bare substrates were measured one day before and one day after the irradiation test. Results are plotted in figs. 5 and 6.
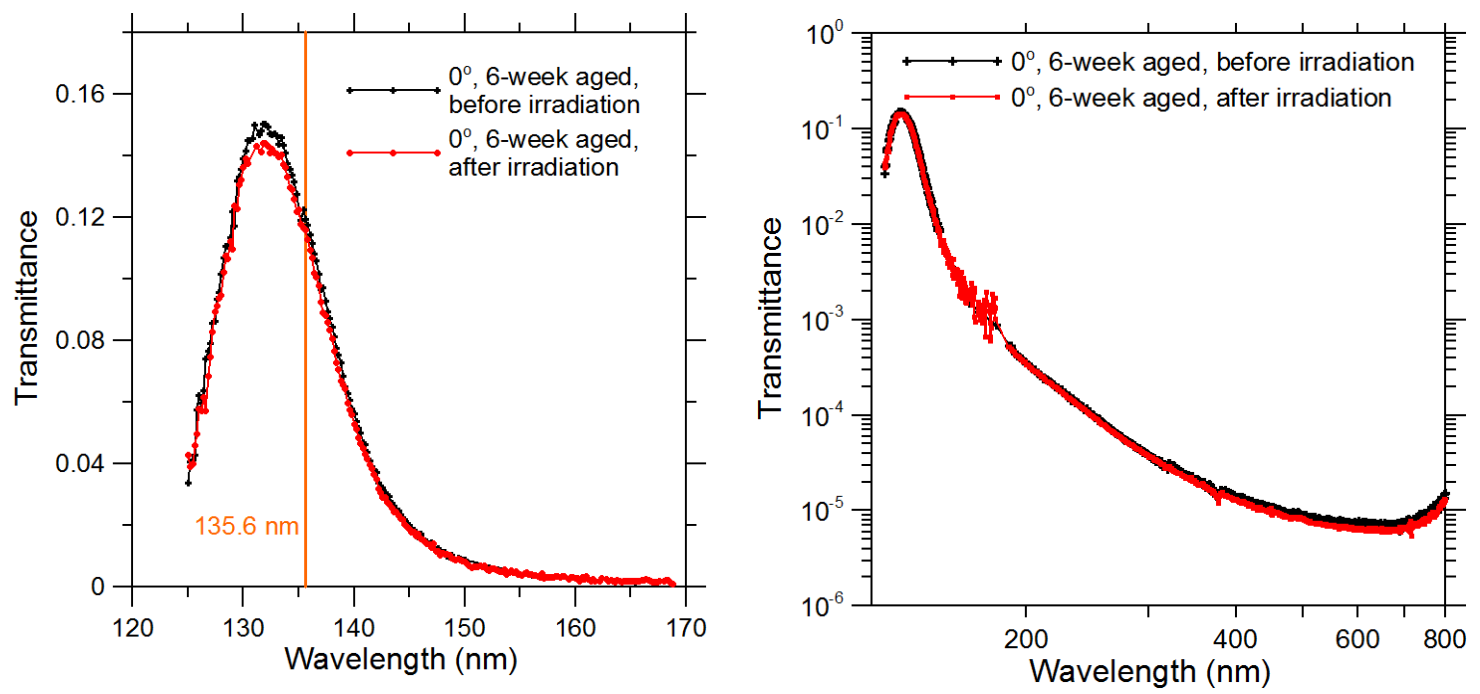

Fig. 5. Transmittance as a function of wavelength of an irradiated filter for the OI line, after 6-week ageing in a desiccator. Measurements were performed one day before and one day after irradiation. Left and right: transmittance and its logarithm, respectively. 

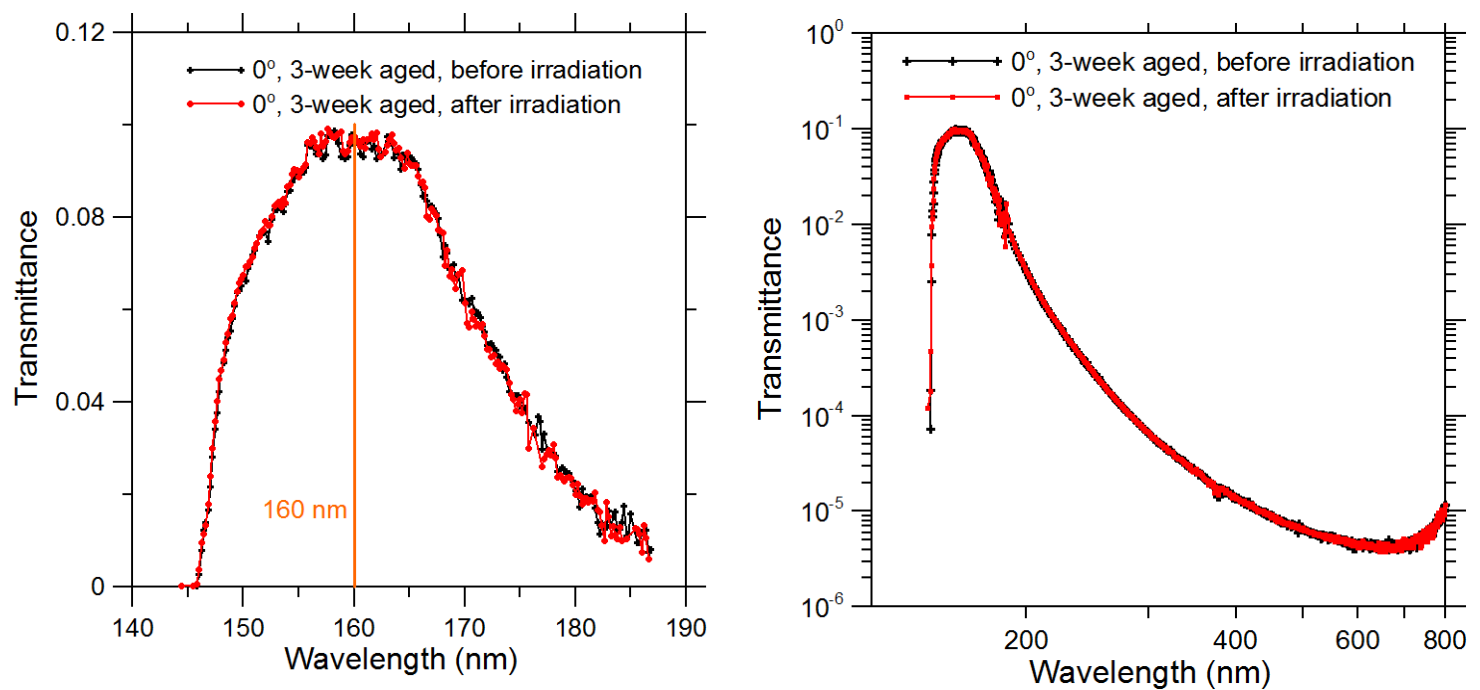

Fig. 6. Transmittance as a function of wavelength of an irradiated filter for the center of the LBH band, after 3-week ageing in a desiccator. Measurements were performed one day before and one day after irradiation. Left and right: transmittance and its logarithm, respectively.

The only change observed was for the filter peaked close to $135.6 \mathrm{~nm}$, with a peak decrease from 0.150 to 0.144 . No changes were detected on the target wavelengths.

\section{CONCLUSIONS}

Transmittance filters were developed for the Ionosphere Photometer mission, aboard the Feng-Yun 3D meteorological satellite. The main requirements for these filters were to have i) peak transmittance at either the Oxygen I line $(135.6 \mathrm{~nm})$ or the central part of the Lyman-Birge-Hopfield band $(\sim 160 \mathrm{~nm})$ and ii) high rejection of the NUV and visible ranges.

Filters based on three-bilayer $\left(\mathrm{Al} / \mathrm{MgF}_{2}\right)_{3}$ coatings were prepared. After some storage in a desiccator, both coatings kept a transmittance of $\sim 0.14$ at their target wavelengths, with visible-to-peak transmittance ratios of $1.2 \cdot 10^{-4}$ (OI filter) and $1.3 \cdot 10^{-4}$ (LBH filter), with a minimum absolute transmittance of $\sim 5 \cdot 10^{-6}$ measured at some visible wavelength for both sorts of filters.

Witness filters were exposed to a 300 Gy radiation dose. No substantial changes in the photometric measurements were detected.

\section{ACKNOWLEDGMENTS}

This research was partly supported by the National Programme for Research, Subdirección General de Proyectos de Investigación, Ministerio de Ciencia e Innovación, project number AYA2010-22032 and AYA201342590-P. The authors are gratefully acknowledged to Pedro Valdivieso (Instalación de irradiación Náyade, CIEMAT) for technical assistance with the irradiation test. We acknowledge Joaquín Campos and Alicia Pons for putting the spectrophotometer at our disposal.

\section{REFERENCES}

${ }^{1}$ D. J. Schoeder, "Interference Transmission Filters for the Far Ultraviolet," J.O.S.A. 52, 12, 1380-86 (1962).

${ }^{2}$ B. Bates, and D. J. Bradley, "Interference Filters for the Far Ultraviolet (1700 ̊ to $2400 \AA$ ),," Appl. Optics, 5, 6, 971 976 (1966). 
${ }^{3}$ D. H. Harrison, "MDM Bandpass Filters for the Vacuum Ultraviolet," Appl. Optics, 7, 1, 210 (1968).

${ }^{4}$ A. Malherbe, M. Guillard "Réalisation industrielle de filtres interférentiels pour l'ultra-violet lointain," Nouv. Rev. Opt. Appl., 1, 401-404 (1970).

${ }^{5}$ E. T. Fairchild, "Interference filters for the VUV (1200-1900 Å)," Appl. Optics, 12, 2240-2241 (1973).

${ }^{6}$ M. Fernández-Perea, J. A. Méndez, J. A. Aznárez, J. I. Larruquert, "Filters for World Space Observatory," in The World Space Observatory Project-Spain, A. I. Gómez de Castro, E. Verdugo, (eds.). Editorial Complutense, Madrid (2006).

${ }^{7}$ A. Malherbe, "Interference filters for the far ultraviolet," Appl. Optics, 13, 1275-1276 (1974).

${ }^{8}$ E. Spiller, "Interference Filters for the Ultraviolet and the Surface Plasmon of Aluminum," Appl. Optics, 13, 5, 12091215 (1974).

${ }^{9}$ E. Shiles, T. Sasaki, M. Inokuti, and D. Y. Smith, "Self-consistency and sum-rule tests in the Kramers-Kronig analysis of optical data: applications to aluminium," Phys. Rev. B, 22, 1612-1628 (1980).

${ }^{10} \mathrm{~J}$. Larruquert, J. Méndez, and J. Aznárez, "Far-ultraviolet reflectance measurements and optical constants of unoxidized aluminum films," Appl. Opt. 34, 22, 4892-4899 (1995).

${ }^{11}$ L. Rodríguez-De Marcos, J. I. Larruquert, J. A. Méndez, J. A. Aznárez, M. Vidal-Dasilva, and L. Fu "Narrowband filters for the FUV range," Proc. SPIE 9144, Space Telescopes and Instrumentation 2014: Ultraviolet to Gamma Ray, 914437 (2014).

${ }^{12}$ J. I. Larruquert, A. M. Malvezzi, A. M. Giglia, A. Aznárez, L. Rodríguez-de Marcos, J. A. Méndez, P. Miotti, F. Frassetto, G. Massone, S. Nannarone, G. Crescencio, G. Capobianco, and S. Fineschi "Reflective and transmissive broadband coating polarizers in a spectral range centered at $121.6 \mathrm{~nm}$," Journal of Optics, 16, 12, 125713-22 (2014).

${ }^{13}$ C. E. Keffer, M. R. Torr, M. Zukic, J. F. Spann, D. G. Torr, and J. Kim, "Radiation Damage Effects in Far Ultraviolet Filters and Substrates," Proc. SPIE 2018, Passive Material for Optical Elements II, 92-103 (1993). 